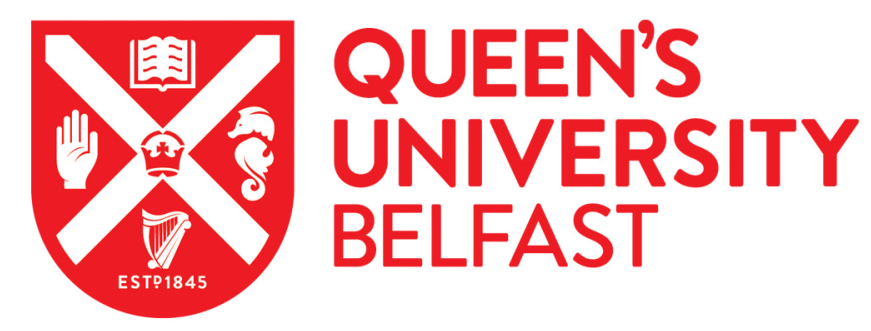

\title{
Association Between Lateral Bias and Personality Traits in the Domestic Dog (Canis familiaris)
}

Barnard, S., Wells, D. L., Hepper, P. G., \& Milligan, A. D. S. (2017). Association Between Lateral Bias and Personality Traits in the Domestic Dog (Canis familiaris). Journal of Comparative Psychology, 131(3), 246-256. https://doi.org/10.1037/com0000074

Published in:

Journal of Comparative Psychology

Document Version:

Peer reviewed version

Queen's University Belfast - Research Portal:

Link to publication record in Queen's University Belfast Research Portal

Publisher rights

(c) 2017 American Psychological Association. This work is made available online in accordance with the publisher's policies. Please refer to any applicable terms of use of the publisher.

\section{General rights}

Copyright for the publications made accessible via the Queen's University Belfast Research Portal is retained by the author(s) and / or other copyright owners and it is a condition of accessing these publications that users recognise and abide by the legal requirements associated with these rights.

Take down policy

The Research Portal is Queen's institutional repository that provides access to Queen's research output. Every effort has been made to ensure that content in the Research Portal does not infringe any person's rights, or applicable UK laws. If you discover content in the Research Portal that you believe breaches copyright or violates any law, please contact openaccess@qub.ac.uk. 
1 Association between lateral bias and personality traits in the domestic dog (Canis familiaris)

2 Barnard Shanis*, Wells Deborah L., Hepper Peter G., Milligan Adam D.S.

3

4 Animal Behaviour Centre, School of Psychology, Queen’s University Belfast, Belfast BT7 1NN,

$5 \quad$ Northern Ireland, UK

6

7 Running title: Lateral bias and personality in the domestic dog 
9 Shanis Barnard, Animal Behaviour Centre, School of Psychology, Queen’s University Belfast, Belfast $10 \quad$ BT7 1NN, Northern Ireland, UK. E-mail: s.barnard@qub.ac.uk

11

12 Acknowledgements

13 The authors would like to thank all the dog owners who volunteered to have their dogs to take part in 14 this study. The financial support of the BBSRC (BB.J021385/1) is gratefully acknowledged. 


\section{Abstract}

16 Behavioural laterality reflects the cerebral functional asymmetry. Measures of laterality have been 17 associated with emotional stress, problem-solving and personality in some vertebrate species. Thus far, the association between laterality and personality in the domestic dog has been largely overlooked. In this study we investigated if lateralised (left or right) and ambilateral dogs differed in their behavioural response to a standardised personality test. The dog's preferred paw to hold a Kong ${ }^{\mathrm{TM}}$ ball filled with food, and the first paw used to step-off from a standing position were scored as laterality measures. The Dog Mentality Assessment (DMA) test was used to assess five personality traits (e.g. Sociability, Aggressiveness) and a broader Shy-Boldness dimension. No differences emerged between left and right biased dogs on any personality trait. Instead, ambilateral dogs, scored using the Kong test, scored higher on their Playfulness $(\mathrm{Z}=-1.98, p=.048)$ and Aggressiveness $(\mathrm{Z}=$ -2.10, $p=.036$ ) trait scores than lateralised (irrespective of side) dogs. Also, ambilateral dogs assessed using the First-stepping test, scored higher than lateralised dogs on the Sociability $(\mathrm{Z}=-2.83, p=$ $.005)$ and Shy-Boldness $(\mathrm{Z}=-2.34, p=.019)$ trait scores. Overall, we found evidence of a link between canine personality and behavioural laterality, and this was especially true for those traits relating to stronger emotional reactivity such as aggressiveness, fearfulness and sociability.

Keywords: canine; dog; laterality; paw preference; personality 


\section{Introduction}

34

In the last two decades, a large body of research has been dedicated to the study of dog personality (Barnard et al., 2016; Fratkin, Sinn, Patall, \& Gosling, 2013; Gartner \& Weiss, 2013; Jones \& Gosling, 2005; Ley, Bennett, \& Coleman, 2008; Svartberg \& Forkman, 2002). The ability to identify personality traits (e.g. fearfulness, playfulness), defined as individual behavioural differences that are consistent across time and situations, has direct applications in assessing the suitability of specific dogs as pets, e.g. to find a good match with prospective owners (Barnard et al., 2016; Dowling-Guyer, Marder, \& D'Arpino, 2011; Valsecchi, Barnard, Stefanini, \& Normando, 2011), or selecting the most fit-for-purpose assistance, working or sporting dogs (Serpell \& Hsu, 2001; Svartberg, 2002; Svobodová, Vápeník, Pinc, \& Bartoš, 2008). The assessment of personality traits may also help in improving dog welfare by identifying individuals that are more likely to experience fear and discomfort in a shelter or laboratory environment (Beerda, Schilder, Van Hooff, De Vries, \& Mol, 1999; Haverbeke, Pluijmakers, \& Diederich, 2015). Unfortunately, personality assessment methods suffer from many limitations (Haverbeke, Pluijmakers, \& Diederich, 2015; Rayment, De Groef, Peters, \& Marston, 2015). Surveys, for example, rely on the owners' perspective and battery tests require resources, standardised protocols, trained researchers and can be very challenging, exposing the dog to a wide range of potential stressors. Finding new associations between personality traits and other easy-to-assess measures may provide new indicators of dogs' behavioural differences without having to use time/resource consuming and challenging techniques.

In humans, affective dispositions and personality have been linked to brain hemisphere asymmetry (Canli et al., 2001; Davidson \& Irwin, 1999; Davidson, 1995; Hagemann et al., 1999). Davidson and colleagues, for example, proposed the 'laterality-valence hypothesis', asserting that each brain hemisphere is specialized in processing different types of emotions (Davidson, 1995). Particularly, negative or withdrawal-related emotions (such as fear or depression) are processed and controlled primarily by the right hemisphere, while positive or approach-related emotions (such as happiness and joy) are controlled mainly by the left hemisphere. In other studies, personality traits such as Extraversion and Neuroticism have been linked with brain asymmetries. Extraversion, for example, 
has been associated with a greater left hemisphere activity (Canli et al., 2001; Hagemann et al., 1999; Howard, Fenwick, Brown, \& Norton, 1992). A large body of research has demonstrated that cerebral specialization is widespread among vertebrates (Rogers \& Andrew, 2002; Rogers, 2010), and that the left and right hemispheres process emotional and environmental information in a different way (MacNeilage, Rogers, \& Vallortigara, 2009; Rogers, Vallortigara, \& Andrew, 2013; Vallortigara, Chiandetti, \& Sovrano, 2011). Some interesting work on domestic dogs, for example, has demonstrated how dogs' asymmetry in tail wagging is associated with the type of visual stimulus the animals are presented with. Results are in line with Davidson's hypothesis: visual stimuli expected to elicit approach tendencies were associated with a higher amplitude of tail wagging movements to the right side (left brain activation), and vice-versa, stimuli expected to elicit withdrawal tendencies were associated with a higher amplitude of tail wagging movements to the left side (right brain activation) (Quaranta, Siniscalchi, \& Vallortigara, 2007; Siniscalchi, Lusito, Vallortigara, \& Quaranta, 2013).

Laterality has been increasingly used in non-human animal research as a predictive indicator of animals' emotional processes, stress reactions and, of more interest for this study, personality traits in different species (sheep: Barnard et al. 2016; dogs: Schneider, Delfabbro, \& Burns, 2013; see also reviews on farm animal species: Leliveld, Langbein, \& Puppe, 2013; Rogers, 2010). For example, boldness has been positively correlated with strength of laterality in cichlids, i.e. strongly lateralised fishes were quicker to emerge from a shelter when exploring an unfamiliar environment than weakly lateralised animals (Reddon \& Hurd, 2009). Likewise, horses assessed as right-hemisphere dominant have been found to be more fearful when presented with unfamiliar stimuli than their left-hemisphere dominant counterparts (Larose, Richard-Yris, Hausberger, \& Rogers, 2006).

Limb preference (i.e. the preferred use of one hand/paw to perform a task) is associated with greater activity of the contralateral motor cortex (Versace \& Vallortigara, 2015). Thus, the observation of a bias in hand (or paw) use can be considered an indicator of brain laterality (Batt, Batt, \& McGreevy, 2007; Branson \& Rogers, 2006; Gordon \& Rogers, 2010; Hopkins \& Bennett, 1994; Marshall-Pescini, 
Barnard, Branson, \& Valsecchi, 2013). This and similar measures of behavioural laterality are relatively easy to employ and non-invasive.

From the limited literature available, there seems to be very little support for a clear relationship between personality traits and laterality in the domestic dog. A study by Branson and Rogers (2006) showed that dogs with stronger paw preferences were less reactive to the sounds of thunderstorms than were those with no significant paw preference bias (i.e. ambilateral). Another study in this area is the one by Schneider and collaborators (2013) which has investigated possible links between paw preference and temperament traits, assessed through an owner-based survey on their pet's behaviour. Their only significant result showed that lateralised dogs scored slightly higher than ambilateral ones on the factor of 'stranger-directed aggression'. In their conclusions, the authors commented that the lack of significant results might be due to the owner-based survey not being sensitive enough to reveal significant relationships with paw preference. They also stressed that, given the effect that aggressive behaviour has on the community, this topic should be investigated further, ideally using a different and more objective measurement of canine personality not vulnerable to owner bias (Schneider et al., 2013).

Drawing on this, the current study aimed to investigate the relationship between personality and lateral bias in the dog using a purposely standardised and validated test battery. To this end, we chose to assess the personality traits in dogs using the Dog Mentality Assessment (DMA) test (Svartberg \& Forkman, 2002; Svartberg, Tapper, Temrin, Radesater, \& Thorman, 2005). The DMA was originally tested on a sample of over 15,000 dogs and the factor analysis based on that sample extracted five personality traits i.e. Playfulness, Curiosity/Fearlessness, Chase-proneness, Sociability, Aggressiveness and a broader Shy-Boldness dimension (Svartberg \& Forkman, 2002). The DMA was tested for reliability and validity, which are unavoidable quality requirements to ensure that the measures are meaningful, appropriate and free from random errors (Svartberg \& Forkman, 2002; Svartberg, 2002; Svartberg, 2005; Svartberg et al., 2005; Taylor \& Mills, 2006). 
115 The dogs' paw preferences were assessed using the widely used Kong ${ }^{\mathrm{TM}}$ ball test (Branson \& Rogers, 116 2006; Marshall-Pescini et al., 2013; Schneider et al., 2013). However, some authors reported some

117 limitations of this tool, such as the task being food-driven (Tomkins, Thomson, \& McGreevy, 2010 118 Plueckhahn, Schneider, \& Delfabbro, 2016). Concerns have also been raised as to whether the main 119 paw used by dogs to stabilise the Kong ${ }^{\mathrm{TM}}$ ball is actually their dominant one (see Wells, Hepper, Milligan, \& Barnard 2016 for discussion). For these reasons, we decided to assess canine paw preference using an additional measure, the First-stepping test, a tool that is reported as being quicker to use than the Kong ${ }^{\mathrm{TM}}$ ball test, repeatable and consistent in time (Tomkins et al., 2010).

It was hoped the study would shed further light on the relationship between lateral bias and personality in the domestic dog and, from an applied perspective, determine whether paw preferences can be used as an indicator of emotional reactivity and vulnerability to stress in a species that is commonly utilised in modern day society.

\subsection{Subjects}

Forty privately owned pet dogs were recruited for this study among the students and staff of the School of Psychology, Queen’s University Belfast, and by word of mouth. Dogs comprised 22 males (81\% neutered) and 18 females (79\% spayed) and included a number of different breeds and breedcrosses. The minimum age of the subjects was 12 months; the oldest dog was 13 years old (mean $\pm \mathrm{SD}$ $4.7 \pm 2.95$ years).

\subsection{Paw preference test}

Following Branson \& Rogers (2006), dogs’ paw preferences were tested using a medium- or smallsized (according to dog size) Kong ${ }^{\mathrm{TM}}$ ball (KONG Company, Golden, CO, USA), a hollow conicalshaped rubber toy (Kong, from now on). Before testing, the toy was filled with moist dog food

141 (Pedigree chum original flavour, Waltham, UK) and frozen overnight. The toys were washed 142 thoroughly in between tests. Dogs were food deprived for at least 4 hours before testing. After 
allowing the dog to sniff the food-loaded Kong for a few seconds, the toy was placed on the floor

144 directly in front of the animal. The experimenter recorded the paw used by the dog to stabilize the

145 Kong. A paw use was classified as the animal having one or both paws on the Kong, regardless of duration. When the animal removed its paw from the Kong and replaced one or both of its paws on the object, it was scored as a separate paw use. The test was considered completed when the dog reached 100 paw uses (left plus right combined). On occasion, dogs used both paws to stabilize the ball; these occurrences were recorded separately and not included in the analysis.

In the First-stepping test, the first paw lifted by the dog in order to walk down a step was recorded on 50 occasions (Tomkins et al., 2010). If a dog was too small for the standard step (height $0.18 \mathrm{~m}$; width $1.40 \mathrm{~m}$ ), i.e. the dog jumped down instead of stepping, we used smaller steps (height $0.05 \mathrm{~m}$; width 1 $\mathrm{m})$. The assistant stood on the upper level of the step next to the dog and held the animal loosely on a lead. The researcher stood on the base level two meters away and facing the pair. When the dog was standing square with its forelegs level on the step, the researcher called the dog and recorded the paw lifted to step off the step. Both the assistant and researcher remained stationary while the dog stepped off. To give the dog a chance to rest and drink, the task was completed over four sets of First-stepping repetitions following the sequence 15-15-10-10. Each time, the assistant alternated her position by standing on the left or right hand-side of the dog.

\subsection{Personality test}

All dogs were tested using a slightly modified version of the Dog Mentality Assessment (DMA) test (Table 1). The original test includes 10 subtests, carried out in an outdoor area (Svartberg \& Forkman, 2002). Due to unstable weather conditions, the test was adapted to be carried out indoors. All subtests were performed, except 'Gunshots', which was considered too stressful from an animal welfare perspective. Since previous work has shown that this variable is not associated with any personality trait extracted by a factor analysis (Svartberg \& Forkman, 2002), this omission did not compromise the analysis of the personality traits scores. 
171 The owner was present at all times during testing, holding the dog on the leash whenever required.

172 Two experimenters (blind to the paw preference scores) tested the dogs; both were unfamiliar to the

173 dogs and were the same throughout the study.

174

The dog's behavioural reactions were scored according to 32 predefined behavioural variables (as described in Svartberg \& Forkman, 2002). Each variable was scored from 1 to 5 according to the intensity of the dog's reaction.

(Table 1 about here)

\subsection{Data management and statistical analysis}

All analyses were carried out using IBM SPSS Statistics 21.0.

Individual paw preference scores were calculated using a binomial test and converted to a $z$-score using the formula $z=(\mathrm{L}-0.5 \mathrm{~N}) / \sqrt{ }(0.25 \mathrm{~N})$, $\mathrm{L}$ being the number of left paw uses and $\mathrm{N}$ the total of left and right paw uses. A $z$-score $\geq 1.96$ indicates a left bias, a $z$-score $\leq-1.96$ indicates a right bias; a value between these two scores indicates no lateral bias (ambilateral) (Branson \& Rogers, 2006, Wells 2003). The left-, right- and ambilateral paw preference classification was used to assess departures from random distribution by applying a Chi-squared test.

A directional laterality index (LI) was calculated to quantify each dog's paw preference on a continuum from strongly left-paw preferent $(+1)$ to strongly right paw-preferent $(-1)$. The LI score was calculated as $(\mathrm{L}-\mathrm{R})$ / $(\mathrm{L}+\mathrm{R})$, where $\mathrm{R}$ represents the number of right paws and $\mathrm{L}$ the number of left paws used (Wells, 2003). A score of 0 indicates no bias, a score of \pm 1 indicates that the subject used the same paw throughout the trial. The directional laterality index was also used to identify any population bias (non-parametric one-sample $t$-test).

In addition to the directional bias of lateral behaviour (i.e. left or right bias), the strength of laterality has also been used as a proxy measure of hemispheric brain activity. Strongly lateralised animals 
show a greater activity of one hemisphere (irrespective of the side), while weakly lateralised animals do not show a significant dominance of one hemisphere over the other (i.e. ambilateral) (Rogers, 2000). The absolute value of LI, gives a measure of the strength of laterality, irrespective of the direction of paw use. A Shapiro-Wilk normality test was used to assess the distribution of LI absolute values.

Any effect of sex on the direction and strength of laterality was calculated using a Mann-Whitney-U test for independent samples.

Associations between the Kong and First-stepping tests on the three lateral bias groups (left, right and ambilateral) were assessed using a Chi-square analysis, while the consistency between tests for both the direction and strength of laterality was assessed using Spearman's correlation test.

Following the results in Svartberg and Forkman (2002), we calculated the dogs' trait scores for the following personality traits: Playfulness, Curiosity/fearlessness, Chase-proneness, Sociability and Aggressiveness. The dog's score (1-5) on each variable was standardized using z-scores (Svartberg et al., 2005). Then, the standardized values for the representative variables of each factor (i.e. variables with high loadings on a factor, according to the results in Svartberg and Forkman2002) were averaged to calculate dogs' personality trait scores. For example, the trait Playfulness was calculated by averaging the standardised values of the variables \#5, 6, 7, 31 and 32 from subtests 'play 1' and play 2' (Table 1). Table 1 shows which are the representative variables for each personality trait. In addition, we calculated a broader Shy-boldness dimension score by averaging the scores for Playfulness, Curiosity/fearlessness, Chase-proneness, and Sociability (following Svartberg et al., 2005).

To ensure that the items included in our new trait scores were measuring the same construct, we examined the internal consistency using Cronbach’s alpha. For the higher Shy-Boldness dimension we calculated the item-to-total correlation using Spearman rank test. 
228 A Kruskal-Wallis test for independent groups was used to determine if left-lateralised (LL), right229 lateralised (RL) and ambilateral (AL) dogs differed in their standardised personality traits scores.

230

231

232

233

234

235

236

237

238

239

240

241

242

243

244

245

246

247

The absolute value of LI was correlated with the personality trait scores using Spearman's correlation test. Furthermore, a Wilcoxon test was used to ascertain whether there were any significant differences between lateralised and ambilateral animals on the personality trait scores. For this latter analysis, dogs defined as left- or right-lateralised, according to z-score calculations, were combined and categorised as lateralised (LAT), and the remaining categorised as ambilateral (AL).

\subsection{Ethical Note}

All methods adhered to the Association for the Study of Animal Behaviour/ Animal Behavior Society Guidelines for the Use of Animals in Research (Association for the Study of Animal Behaviour, 2006). Ethical approval for the study was granted by the Research Ethics Committee, School of Psychology, QUB.

\section{Results}

\subsection{Paw preference}

Paw preferences were not successfully recorded for three dogs using the Kong test $(n=37)$ and 2 dogs using the First-stepping test $(\mathrm{n}=38)$. These dogs were therefore removed from the remaining analyses. Lateralisation at the individual level for both tests is reported in Table 2.

(Table 2 about here) 
The distribution of the three paw preference categories did not differ significantly from that expected by chance, i.e. there was no population level effect (Kong: $\chi_{2,37}^{2}=0.87, p=.65$; First-stepping: $\chi^{2}{ }_{2,38}=$ $5.11, p=.08$ ). Even when exploring the direction of laterality (using LI scores), neither test revealed a population level bias (Kong: $\mathrm{Z}=.84, p=.48$; First-stepping: $\mathrm{Z}=.80, p=0.55$; Figure 1 ).

\section{(Figure 1 about here)}

Instead, the distribution of the absolute strength of laterality was significantly skewed towards weakly lateralised animals (median $=|0.28|$ ) (Shapiro-Wilk: Kong, $\mathrm{W}=.91 ; p=.007$; First-stepping, $\mathrm{W}=0.92$, $p=.008)$.

Direction and strength of laterality were not significantly affected by the sex of the dogs (Kong: $\mathrm{Z}_{L I}=$ -.87, $p=.39 ; \mathrm{Z}_{|L I|}=-.84, p=.40$; First-stepping: $\mathrm{Z}_{L I}=-.63, p=.53 ; \mathrm{Z}_{|L I|}=-1.06, p=.30$ ).

Only $34.3 \%(n=12)$ of the dogs showed a consistent paw classification between the two tests, whereas $45.0 \%$ of dogs that had a significant individual bias (left or right) during the Kong test were recorded as ambilateral on the First-stepping test. There was no significant association between the two laterality tests for the three categories of paw use $\left(\chi_{4,35}^{2}=2.20, p=.70\right)$ and there was no correlation between tests for direction $(\mathrm{R}=-.17, p=.34)$ or strength $(\mathrm{R}=.19, p=.28)$ of laterality.

\subsection{Personality assessment}

After creating the personality trait scores, we checked for their internal consistency. Alpha values were acceptably high for all of the five traits: Playfulness (0.93), Curiosity/Fearlessness (0.81), Chaseproneness (0.86), Sociability (0.72), and Aggressiveness (0.65).

The item-to-total correlation scores were significant $(p \leq .01)$ for the four traits that were averaged to calculate the Boldness trait (Playfulness, Curiosity/Fearlessness, Chase-proneness and Sociability). 
However, the correlation between the traits Aggressiveness and Shy-Boldness was not significant, confirming previous results (Svartberg et al., 2005).

\subsection{Association between lateral behaviour and personality traits}

The three laterality groups (LL, RL and AL) assessed with the Kong test did not differ significantly in any of their personality scores ( $p>.05$ for all traits). However, an overall significant relationship emerged between laterality group and traits of Sociability $(\mathrm{K}=8.4, p=.02)$ and Shy-Boldness $(\mathrm{K}=$ 7.3, $p=.03$ ) using the First-stepping test (Figure 2). Post-hoc comparisons showed that AL scored consistently higher than LL dogs (Sociability: $\mathrm{Z}=-2.53, p=.011$; Shy-Boldness: $\mathrm{Z}=-2.61, p=.009$ ) and AL also scored higher than RL dogs for the Sociability trait (Sociability: $\mathrm{Z}=-2.14, p=.033$; ShyBoldness: $\mathrm{Z}=-1.35, p=.18$ ). No significant difference was recorded between left- and rightlateralised dogs for these traits (Sociability: $\mathrm{Z}=-.70, p=.48$; Shy-Boldness: $\mathrm{Z}=-1.4, p=.16$ ).

(Figure 2 about here)

There was one negative correlation (significant after Bonferroni correction $(p \leq .008)$ between the dogs' strength of laterality $(|\mathrm{LI}|)$ scores on the First-stepping test and the personality trait of Sociability ( $\rho=-.50, p=.002$, Figure 3 ). Increasing strength of laterality was associated with lower scores on this trait.

(Figure 3 about here)

Since the main trend seemed to be that the ambilateral dogs (AL, i.e. weakly lateralised) differed from the other groups (LL and RL), an additional analysis was carried out to compare AL to LAT animals. Ambilateral (AL) dogs (assessed with the Kong test) scored significantly higher than LAT dogs on the traits of Playfulness $(\mathrm{Z}=-1.98, p=.048)$ and Aggressiveness $(\mathrm{Z}=-2.10, p=.036)$ (Figure 4). Further, a significant difference between LAT and AL groups assessed with the First-stepping test 
emerged for both the traits of Sociability $(\mathrm{Z}=-2.83, p=.005)$ and Shy-Boldness $(\mathrm{Z}=-2.34, p=.019)$, with AL scoring higher than LAT dogs on both traits.

(Figure 4 about here)

\section{Discussion}

In this study, we investigated the possible association between paw preference (assessed using two different tasks) and individual differences in personality traits (assessed using a validated and standardised test) in the domestic dog. Our main findings were that ambilateral dogs, scored using the Kong test, scored higher on their Playfulness and Aggressiveness trait scores than lateralised dogs. Also, ambilateral dogs, assessed using the First-stepping test, scored higher than lateralised dogs on the Sociability and Shy-Boldness trait scores.

Results from the paw preference tests revealed a significant lateral bias at the individual level (Kong test $59.4 \%$ vs First-stepping test 50\% lateralised dogs); there was no evidence of a population bias. Previous literature reports contrasting results in this respect, with some studies showing an equal distribution of paw use between lateralised and ambilateral dogs (Marshall-Pescini et al., 2013; Poyser, Caldwell, \& Cobb, 2006; Schneider et al., 2013) and some not (Branson \& Rogers, 2006; Siniscalchi et al., 2008). We also did not find a sex bias on lateral behaviour, which again is in line with a number of studies (Branson \& Rogers, 2006; Marshall-Pescini et al., 2013; Schneider et al., 2013), and in contrast with others (Poyser et al., 2006; Wells, 2003). Overall, it seems there is still the need for further investigations to clarify the factors affecting lateral bias in dogs.

Analysis showed that most dogs (66\%) were not consistent in their paw use between the two tasks. This is consistent with previous results by Tomkins et al. (2010) who reported that only one third of their subjects consistently used the same paw between tests (i.e. the Kong and the First-stepping test). Previous papers have also reported low consistency in lateral bias across different tasks, strengthening 
the hypothesis that paw preference in dogs may be task dependent (Tomkins, McGreevy, \& Branson, 2010; Batt, Batt, Baguley, \& McGreevy, 2008; Wells, 2003). So far very little insight has been given on the mechanisms underlying the preferential use of one paw over the other according to task complexity or nature of challenge, e.g. food on non-food driven, so more work is needed to explore this further.

The DMA test was originally tested on a large sample of dogs and the factor analysis based on that sample extracted the five personality dimensions and a higher Boldness trait that were used in this study (Svartberg \& Forkman, 2002). Given that each dimension was represented by several behavioural variables, we checked for internal consistency and item-to-total correlation to ensure that our variables were measuring the same constructs. Cronbach's alpha was acceptably high for all factors (>0.70); Aggressiveness was the lowest (0.65), but Svartberg et al. (2005) found very similar results (0.67), probably due to aggressive behaviour being very context specific (Christensen, Scarlett, Campagna, \& Houpt, 2007). The correlation between the Shy-Boldness dimension and the five personality traits also confirmed that Aggressiveness was unrelated to the other traits, i.e. Playfulness, Chase-proneness, Curiosity/Fearlessness and Sociability (Svartberg \& Forkman, 2002; Svartberg et al., 2005).

When exploring for associations between paw preference and personality traits, the analysis revealed no significant effect of the direction of laterality on any of the personality traits. Our findings, instead, suggested a relationship between the strength of laterality and some of the dogs' personality traits. This relationship varied according to the task that was used to assess paw preference. Ambilateral dogs classified using the Kong test, scored higher on both the Playfulness and Aggressiveness traits compared to lateralised dogs (including both LL and RL). The right hemisphere is specialised in detecting and responding to novel stimuli and controlling emergency responses (e.g. fear, escape, aggression), thus aggressiveness seems to be highly lateralised in a wide range of vertebrates, ranging from primates to fish (Austin \& Rogers, 2014; Rogers \& Andrew, 2002). However, it is also reported that weakly lateralised animals are more likely to react in a less adaptive way to challenging 
361 situations, showing distress and reacting more strongly to a threat (Branson \& Rogers, 2006;

362 Dharmaretnam \& Rogers, 2005). Branson and Rogers (2006), for example, found that dogs with a

363 weaker paw preference (as assessed using the Kong Test) were more prone to distress in response to

364 loud noises than animals that were more strongly lateralised. The Aggressiveness trait in this study 365 was calculated on the basis of the response elicited by exposing the dog to a series of sudden and 366 threatening stimuli, e.g. ghost test. Thus, most reactions were fear-driven and associated with a lower posture and increased distance from the stimuli, which may suggest that weakly lateralised dogs were struggling to cope with the challenging/fear-eliciting situation.

It is less clear why weakly lateralised dogs, assessed with the Kong task, were also more playful. It could be that ambilateral dogs were overall more reactive to both positive and negative emotionallyarousing stimuli. The test environment is novel and challenging, which is known to be somewhat stressful for dogs (Planta \& De Meester, 2007). It is worth pointing out that the $p$-value for this comparison was just below chance level (0.048). When correlating the $|\mathrm{LI}|$ index score (measuring the strength of laterality) with the Playfulness and Aggressiveness trait, this relationship was not confirmed. The $|\mathrm{LI}|$ index, being a continual variable, offers greater statistical power than the paw preference categories (Tomkins et al., 2010). These results should therefore be confirmed with a larger sample size.

Paw preference classifications determined using the First-stepping test also differed significantly on two personality traits: Sociability and Shy-Boldness. Again, ambilateral dogs scored higher on both of these traits. The difference appeared to be mainly due to left-biased dogs scoring consistently lower than right or ambilateral animals, weakly supporting the hypothesis that right-hemisphere dominance is associated with a less-bold/more-shy temperament (Hopkins \& Bennett, 1994). The strong correlation between strength of laterality and the trait of Sociability seems to support Batt et al.'s (2009) finding that dogs with a weaker paw preference were more excitable when approaching an unfamiliar person than animals which were more strongly lateralised. When scoring the greeting behaviour during the test, a higher score was given to dogs that showed 'intense greeting with 
jumping and whining', thus describing more excitable dogs. However, another study in this area employed an owner-based survey (the Canine Behavioral Assessment and Research Questionnaire, Hsu \& Serpell, 2003) to define behavioural categories (Schneider et al. 2013). They found no correlation between the C-BARQ subscale 'excitability' and the strength of laterality. The authors argued that the different results might lie in the different contexts in which this trait was assessed: the C-BARQ subscale refer to events that are familiar to the dog (e.g. playing with the owner in the household), whereas in Batt et al.'s (2009) study there is an element of novelty implicit in the test situation. This would be in line with our findings, as our dogs were also presented with an unfamiliar person in a novel environment. Further investigation should be carried out to get more insight on this aspect.

\section{Conclusion}

This study is the first of its kind to examine the relationship between the direct assessment of personality traits in dogs and paw preference using both the Kong and the First-stepping test. We found evidence of a link between canine personality, especially those traits relating to stronger emotional reactivity such as aggressiveness, fearfulness and sociability, and behavioural laterality. Interestingly, the strongest correlation (i.e. between the strength of laterality and the Sociability trait) emerged when the dogs' paw preference was assessed using the First-stepping test and not the more commonly applied Kong test. The use of laterality as a proxy measure for behavioural differences in animals is an area gaining increasing attention across many different species. The ease of access to dog populations and the important applied outcomes of defining reliable and easy to apply measures of personality (i.e. good owner-dog match, reduced welfare risk in shelters, predicting suitable working dogs) makes the dog a perfect model to further explore the link between different measures of laterality and personality traits. 
Austin, N., \& Rogers, L. (2014). Lateralisation of agonistic and vigilance responses in przewalski horses (Equus przewalskii). Applied Animal Behaviour Science, 151, 43-50.

Barnard, S., Matthews, L., Messori, S., Podaliri-Vulpiani, M., \& Ferri, N. (2016). Laterality as an indicator of emotional stress in ewes and lambs during a separation test. Animal Cognition,

Barnard, S., Marshall-Pescini, S., Passalacqua, C., Beghelli, V., Capra, A., Normando, S., . . .Valsecchi, P. (2016). Does subjective rating reflect behavioural coding? Personality in 2 monthold dog puppies: An open-field test and adjective-based questionnaire. Plos One, 11(3),

Branson, N. J., \& Rogers, L. J. (2006). Relationship between paw preference strength and noise phobia in canis familiaris. Journal of Comparative Psychology, 120(3), 176-183. 
Canli, T., Zhao, Z., Desmond, J. E., Kang, E., Gross, J., \& Gabrieli, J. D. (2001). An fMRI study of personality influences on brain reactivity to emotional stimuli. Behavioral Neuroscience, 115(1), 33.

Christensen, E., Scarlett, J., Campagna, M., \& Houpt, K. A. (2007). Aggressive behavior in adopted dogs that passed a temperament test. Applied Animal Behaviour Science, 106(1-3), 85-95.

Davidson, R. J., \& Irwin, W. (1999). The functional neuroanatomy of emotion and affective style. Trends in Cognitive Sciences, 3(1), 11-21.

Davidson, R. J. (1995). Cerebral asymmetry, emotion, and affective style. In R. J. D. K. Hugdahl (Ed.), Brain asymmetry (pp. 361-387). Cambridge, MA, US: The MIT Press.

Dharmaretnam, M., \& Rogers, L. J. (2005). Hemispheric specialization and dual processing in strongly versus weakly lateralised chicks. Behavioural Brain Research, 162(1), 62-70.

Dowling-Guyer, S., Marder, A., \& D'Arpino, S. (2011). Behavioral traits detected in shelter dogs by a behavior evaluation. Applied Animal Behaviour Science, 130(3-4), 107-114. doi:10.1016/j.applanim.2010.12.004

Fratkin, J. L., Sinn, D. L., Patall, E. A., \& Gosling, S. D. (2013). Personality consistency in dogs: A meta-analysis. PLoS One, 8(1), e54907.

Gartner, M. C., \& Weiss, A. (2013). Personality in felids: A review. Applied Animal Behaviour Science, 144(1), 1-13.

Gordon, D. J., \& Rogers, L. J. (2010). Differences in social and vocal behavior between left- and right-handed common marmosets (callithrix jacchus). Journal of Comparative Psychology, 124(4), 402-411. 
Hagemann, D., Naumann, E., Lürken, A., Becker, G., Maier, S., \& Bartussek, D. (1999). EEG asymmetry, dispositional mood and personality. Personality and Individual Differences, 27(3), $541-568$

Haverbeke, A., Pluijmakers, J., \& Diederich, C. (2015). Behavioral evaluations of shelter dogs: Literature review, perspectives, and follow-up within the european member states's legislation with emphasis on the belgian situation. Journal of Veterinary Behavior-Clinical Applications and Research, 10(1), 5-11. doi:10.1016/j.jveb.2014.07.004

Hopkins, W. D., \& Bennett, A. J. (1994). Handedness and approach-avoidance behavior in chimpanzees (Pan). Journal of Comparative Psychology, 20(4), 413-418.

Howard, R., Fenwick, P., Brown, D., \& Norton, R. (1992). Relationship between CNV asymmetries and individual differences in cognitive performance, personality and gender. International Journal of Psychophysiology, 13(3), 191-197.

Hsu, Y., \& Serpell, J. A. (2003). Development and validation of a questionnaire for measuring behavior and temperament traits in pet dogs. Journal of the American Veterinary Medical Association, 223(9), 1293-1300.

Jones, A. C., \& Gosling, S. D. (2005). Temperament and personality in dogs (canis familiaris): A review and evaluation of past research. Applied Animal Behaviour Science, 95(1-2), 1-53.

Larose, C., Richard-Yris, M., Hausberger, M., \& Rogers, L. J. (2006). Laterality of horses associated with emotionality in novel situations. Laterality, 11(4), 355-367.

Leliveld, L. M., Langbein, J., \& Puppe, B. (2013). The emergence of emotional lateralisation: Evidence in non-human vertebrates and implications for farm animals. Applied Animal Behaviour Science, 145(1), 1-14. 
Ley, J., Bennett, P., \& Coleman, G. (2008). Personality dimensions that emerge in companion canines. Applied Animal Behaviour Science, 110(3-4), 305-317. doi:http://dx.doi.org/10.1016/j.applanim.2007.04.016

MacNeilage, P. F., Rogers, L. J., \& Vallortigara, G. (2009). Origins of the left and right brain. Scientific American, 301(1), 60-67.

Marshall-Pescini, S., Barnard, S., Branson, N. J., \& Valsecchi, P. (2013). The effect of preferential paw usage on dogs' (Canis familiaris) performance in a manipulative problem-solving task. Behavioural Processes, 100, 40-43.

Planta, J. U. D., \& De Meester, R. H. W. M. (2007). Validity of the socially acceptable behavior (SAB) test as a measure of aggression in dogs towards non-familiar humans. Vlaams Diergeneeskundig Tijdschrift, 76(5), 359-368.

Plueckhahn, T. C., Schneider, L. A., \& Delfabbro, P. H. (2016). Assessing lateralization in domestic dogs: Performance by Canis familiaris on the Kong test. Journal of Veterinary Behavior: Clinical Applications and Research, 15, 25-30.

Poyser, F., Caldwell, C., \& Cobb, M. (2006). Dog paw preference shows lability and sex differences. Behavioural Processes, 73(2), 216-221.

Quaranta, A., Siniscalchi, M., \& Vallortigara, G. (2007). Asymmetric tail-wagging responses by dogs to different emotive stimuli. Current Biology, 17(6), R199-201.

Rayment, D. J., De Groef, B., Peters, R. A., \& Marston, L. C. (2015). Applied personality assessment in domestic dogs: Limitations and caveats. Applied Animal Behaviour Science, 163, 1-18.

Reddon, A. R., \& Hurd, P. L. (2009). Individual differences in cerebral lateralisation are associated with shy-bold variation in the convict cichlid. Animal Behaviour, 77(1), 189-193. 
502

503

504

505

506

507

508

509

510

511

512

513

514

515

516

517

518

519

520

521

522

523

524

Rogers, L. J., \& Andrew, R. (2002). Comparative vertebrate lateralisation. Cambridge University Press, Cambridge , UK.

Rogers, L. J. (2010). Relevance of brain and behavioural lateralisation to animal welfare. Applied Animal Behaviour Science, 127(1), 1-11.

Rogers, L. J., Vallortigara, G., \& Andrew, R. J. (2013). Divided brains: The biology and behaviour of brain asymmetries. Cambridge University Press, Cambridge, UK.

Schneider, L. A., Delfabbro, P. H., \& Burns, N. R. (2013). Temperament and lateralisation in the domestic dog (Canis familiaris). Journal of Veterinary Behavior: Clinical Applications and Research, 8(3), 124-134.

Serpell, J. A., \& Hsu, Y. (2001). Development and validation of a novel method for evaluating behaviour and temperament in guide dogs. Applied Animal Behaviour Science, 72, 347-364.

Siniscalchi, M., Lusito, R., Vallortigara, G., \& Quaranta, A. (2013). Seeing left- or right-asymmetric tail wagging produces different emotional responses in dogs. Current Biology, 23(22), 22792282. doi:10.1016/j.cub.2013.09.027

Siniscalchi, M., Quaranta, A., \& Rogers, L. (2008). Hemispheric specialization in dogs for processing different acoustic stimuli. PLoS ONE, 3(10), e3349.

Svartberg, K., \& Forkman, B. (2002). Personality traits in the domestic dog (Canis familiaris). Applied Animal Behaviour Science, 79(2), 133-155.

Svartberg, K. (2002). Shyness and boldness predicts performance in working dogs. Applied Animal Behaviour Science, 79, 157-174.

Svartberg, K. (2005). A comparison of behaviour in test and in everyday life: Evidence of three consistent boldness-related personality traits in dogs. Applied Animal Behaviour Science, 91, 103-128. 
Svartberg, K., Tapper, I., Temrin, H., Radesater, T., \& Thorman, S. (2005). Consistency of personality traits in dogs. Animal Behaviour, 69, 283-291.

Svobodová, I., Vápeník, P., Pinc, L., \& Bartoš, L. (2008). Testing german shepherd puppies to assess their chances of certification. Applied Animal Behaviour Science, 113(1), 139-149.

Taylor, K. D., \& Mills, D. S. (2006). The development and assessment of temperament tests for adult companion dogs. Journal of Veterinary Behavior: Clinical Applications and Research, 1(3), 94108.

Tomkins, L. M., McGreevy, P. D., \& Branson, N. J. (2010). Lack of standardization in reporting motor laterality in the domestic dog (Canis familiaris). Journal of Veterinary Behavior: Clinical Applications and Research, 5(5), 235-239.

Tomkins, L. M., Thomson, P. C., \& McGreevy, P. D. (2010). First-stepping test as a measure of motor laterality in dogs (Canis familiaris). Journal of Veterinary Behavior: Clinical Applications and Research, 5(5), 247-255.

Vallortigara, G., Chiandetti, C., \& Sovrano, V. A. (2011). Brain asymmetry (animal). Wiley Interdisciplinary Reviews: Cognitive Science, 2(2), 146-157

Valsecchi, P., Barnard, S., Stefanini, C., \& Normando, S. (2011). Temperament test for re-homed dogs validated through direct behavioral observation in shelter and home environment. Journal of Veterinary Behavior: Clinical Applications and Research, 6(3), 161-177.

Versace, E., \& Vallortigara, G. (2015). Forelimb preferences in human beings and other species: Multiple models for testing hypotheses on lateralization. Frontiers in Psychology, 6, 233. doi:10.3389/fpsyg.2015.00233

Wells, D. L. (2003). Lateralised behaviour in the domestic dog, Canis familiaris. Behavioural Processes, 61(1), 27-35. 
548 Wells, D. L., Hepper, P. G., Milligan, A. D., \& Barnard, S. (2016). Comparing lateral bias in dogs and 549 humans using the Kong ${ }^{\mathrm{TM}}$ ball test. Applied Animal Behaviour Science, 176, 70-76 
552 Figure 1 Boxplots show the LI scores variability of the three paw preference groups (left-lateralised

553 (LL), right-lateralised (RL) and ambilateral (AL)) for the Kong test (a) and First-stepping test (b).

554 Values are medians (bar within the box), upper and lower quartiles (borders of box), lowest and

555 highest cases within 1.5 times the IQR (bottom and top whiskers) and outliers (circles and asterisks).

556 Figure 2 Comparison between the three laterality groups (left-lateralised (LL), right-lateralised (RL)

557 and ambilateral (AL)) for the Sociability (a) and Shy-Boldness (b) traits.

558 Figure 3 Correlation between the First-stepping strength of laterality (absolute LI value) and the 559 personality trait score Sociability.

560 Figure 4 Comparison between lateralised (LAT) and ambilateral (AL) dogs for traits of Playfulness 561 (a) and Aggressiveness (b). 